\title{
Evaluation of raw and chemically treated waste phosphogypsum and its potential applications
}

\author{
Tebogo Mashifana* \\ University of Johannesburg, Department of Chemical Engineering Technology, P.O. Box 17011, Doornfontein 2088, South Africa
}

\begin{abstract}
A million tons of Phosphogypsum (PG) is stacked in the environment every year and is progressively considered an asset. South African construction industry is expanding as a result of infrastructural developments in the country, the reuse of PG in this industry is considered for recycling and reducing the stacks in landfills. Phosphogypsum is known for its limited ability to use in cement industry due to its phosphorus and radionuclides impurities. This study was conducted to reduce these impurities and investigate the probability of PG application in building and construction. Leaching of PG with citric acid was conducted whereby a relative proportion of $\mathrm{P}_{2} \mathrm{O}_{5}$ and radionuclides was reduced in the material, constituents which contributes to strengths reduction. Optimum moisture Contents and maximum dry densities were determined for various PG content mix designs in which Lime and Fly Ash were added to stabilise PG material. The composites were compacted at various moisture contents and cured at low and elevated temperatures of at $40{ }^{\circ} \mathrm{C}$ and $80{ }^{\circ} \mathrm{C}$ for 4 days. The results obtained shows that for unconfined compressive strengths; the composites produced from $\mathrm{PG}$, and cured at high temperature qualified for the use in construction industry.
\end{abstract}

\section{Introduction}

Environmental problems do not only take a lead in the reported crisis but also threatens the existence of humanity in the near future. Designing an environmental friendly, sustainable products and processes is a major problem in the developing country like South Africa. In addition to that, engineers have to find new ways to recycle and re-use all the alleviating percentage of accumulated by-products. South Africa has limited resources and this makes it a necessity for the adoption of a number of policies, such as pollution prevention, and recycling of waste material for better use. South Africa has a highly developed domestic and export oriented phosphate industry, with the largest igneous phosphates deposits located in Phalaborwa in the northern province of the country [1]. Residual deposits of Phosphogypsum are readily available in large quantities in South Africa and currently are landfilled or pumped into the sea [2]. Waste Phosphogypsum is produced as a by-product during the treatment of phosphate concentrates with sulphuric acid to produce phosphoric acid according to the following simplified chemical reaction [3].

$\mathrm{CaF}_{2} \cdot 3 \mathrm{Ca}_{3}\left(\mathrm{PO}_{4}\right)_{2}+10 \mathrm{H}_{2} \mathrm{SO}_{4}+20 \mathrm{H}_{2} \mathrm{O}=6 \mathrm{H}_{3} \mathrm{PO}_{4}+10$ $\mathrm{CaSO}_{4} \cdot 2 \mathrm{H}_{2} \mathrm{O}+2 \mathrm{HF}$

The Phosphogypsum produced can appear as a di-hydrate $\left(\mathrm{CaSO}_{4} \cdot 2 \mathrm{H}_{2} \mathrm{O}\right)$ or hemi-hydrate $\left(\mathrm{CaSO}_{4} \cdot 1 / 2 \mathrm{H}_{2} \mathrm{O}\right)$ form depending on the processing form [3]. This by-product is then filtered from the produced phosphoric acid aqueous solution and then transferred as a wet cake to open air storages [4]. The storage of PG without any prior treatment requires large land areas and may lead to serious environmental contamination of soils, water and the atmosphere. For instance the elements present in the PG may be leached and deposited into nearby soil and water systems, and finally to animals and humans.

Soil compaction means applying external pressure to the soil mass so that its characteristic properties improve with regard to construction purposes. $100 \times 100 \mathrm{~mm}$ mould were used for compaction of material after stabilising with Fly Ash and lime. Three layer techniques wasused for specimen casting.

With reference to TRH4 [5], Phosphogypsum is classified under Cemented Materials (C1-C4) this is due to that it is initially elastic and have limited tensile strength. They also crack during drying as a result of shrinkage. Thus it is necessary treat it with lime to reduce the cracks. A C2 material may be used when a non -pumping, erosion resistant layer is required. Both $\mathrm{C} 3$ and $\mathrm{C} 4$ materials can be used in place of natural gravel layers in base and subsets. They can either be cement treated or lime treated depending on the natural properties of the material. However their long term Durability and resistance to erosion has to be carefully tested [TRH4] [5].

The aim of this research was to enhance the geochemical and geotechnical properties of Phosphogypsum (PG) for the use as a building and construction material.

\section{Experimental}

Corresponding author: tmashifana@uj.ac.za 


\subsection{Leaching of and preparation of phosphogypsum Elemental compositions before leaching}

A $20 \mathrm{~L}$ reactor was used for the experiment and $0.5 \mathrm{M}$ of citric acid was used as the concentration for the leaching reagent. Leaching tests were carried over 24 hours, thereafter the sample was filtered, the solids were dried in the oven at $50{ }^{\circ} \mathrm{C}$ and the solution was stored for further analysis. The lumps of the dried solids were broken to $80 \%-75 \mu$. This is the material referred to as treated PG. After treating PG, geotechnical and geochemical tests were conducted. Maximum dry density (MDD) and Optimum Moisture Content (OMC) of the treated PG was determined. A schematic diagram for the leaching process conducted is shown in Figure 1.

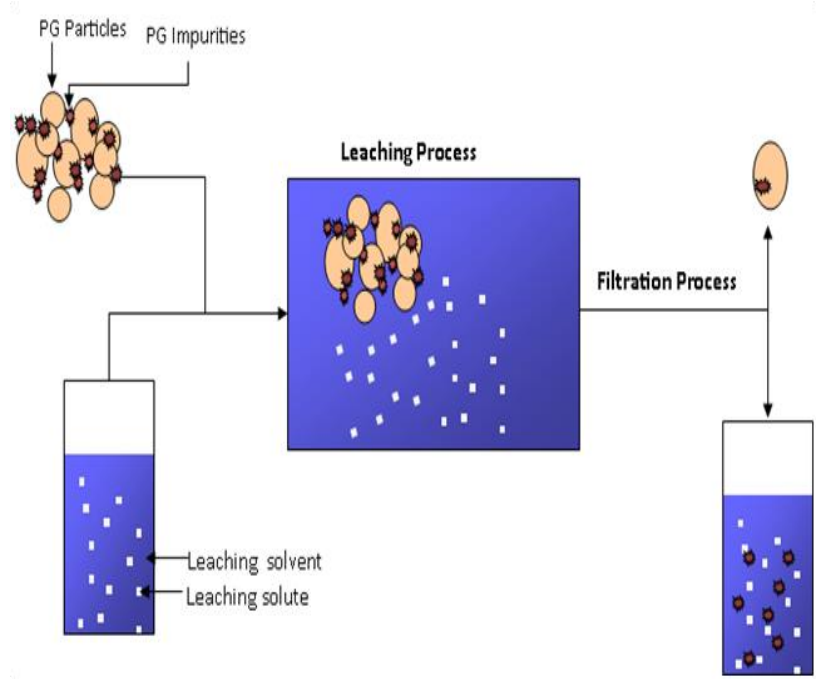

Fig. 1. PG leaching process.

\subsection{Mix Designs preparations, casting and curing}

Four different mix designs were prepared for both Raw and treated PG, the designs were composed of Lime, Fly ash and the material of interest PG. In all designs the percentage by weight ( $\mathrm{w} \%)$ of Lime was kept constant at $20 \%$ while PG and Fly Ash were varied. The proportion of PG was decreases by ten percent from $60 \%$ in design 1 , to $30 \%$ in design 4 . While Fly Ash proportion was increased by ten percent in each design from $20 \%$ in design 1 to $50 \%$ percent in design 4 . The MDD and the OMC obtained were mixed per design. The mixture was then cast into a $100 \mathrm{~mm} \times 100 \mathrm{~mm}$ mould. The moulds were then re-assembled and the moulded sample removed as a specimen. The specimen were tightly covered with a plastic sample bag before being placed into an oven at 40 ${ }^{\circ} \mathrm{C}$ for five days. This procedure was repeated for $80{ }^{\circ} \mathrm{C}$ and $100{ }^{\circ} \mathrm{C}$ specimen.

\subsection{Testing of PG specimen}

After five days the specimen were removed from the oven and the Unconfined Compressive Strength (UCS) test performed on them. After UCS testing a small portion of a specimen was milled using a rod mill and the milled sample were analyzed using XRF for elemental composition. Of the four designs at $40{ }^{\circ} \mathrm{C}, 80^{\circ} \mathrm{C}$ and 100 ${ }^{\circ} \mathrm{C}$, two designs that showed high or better UCS at their respective temperatures were chosen for casting of specimen that were tested for durability. For durability tests two specimen per design were cast, covered with a plastic and cured in the oven for five days. After five days the specimen were removed from the oven weighed (Wi) in a mass scale and fully submerged in water for 24 hours (without plastic). After 24 hours they were removed from the water and weighed (WF) after removing excess water from the specimen, then the UCS test performed.

\section{Results and discussion}

\subsection{XRF analysis of phosphogypsum}

The XRF analyses results for the Raw and Treated PG are illustrated in Table 1.

\begin{tabular}{|c|c|c|}
\hline Component & Raw PG & Treated PG \\
\hline $\mathrm{F}$ & 1.06 & 0.86 \\
\hline $\mathrm{Na}_{2} \mathrm{O}$ & 0.07 & 0.06 \\
\hline $\mathrm{MgO}$ & 0.08 & 0.02 \\
\hline $\mathrm{Al}_{2} \mathrm{O}_{3}$ & 0.23 & 0.23 \\
\hline $\mathrm{SiO}_{2}$ & 1.37 & 1.52 \\
\hline $\mathrm{P}_{2} \mathrm{O}_{5}$ & 1.28 & 0.84 \\
\hline $\mathrm{SO}_{3}$ & 51.01 & 50.31 \\
\hline $\mathrm{K}_{2} \mathrm{O}$ & 0.02 & 0.02 \\
\hline $\mathrm{CaO}$ & 43.65 & 44.85 \\
\hline $\mathrm{Fe}_{2} \mathrm{O}_{3}$ & 0.12 & 0.14 \\
\hline Radionuclides & 1.11 & 0.08 \\
\hline
\end{tabular}

The main targeted impurity was phosphorus and purification was successfully achieved as the relative proportion of $\mathrm{P}_{2} \mathrm{O}_{5}$ decreased by an enormous $34.7 \%$. The $\mathrm{CaO}$ relative proportion increased by $2.7 \%$. The relative proportion of $\mathrm{F}$ and total radionuclides were also decreased, indicating that these components had a significant reaction with Citric acid concentration reducing the impurities and rendering $\mathrm{PG}$ more environmentally friendly by reducing the level of radioactive particles. The constituent that was leached out in a higher percentage is that of Magnesium Oxide $\mathrm{MgO}$ with a relative proportion of $72.3 \%$. According to Liz et al. (2004), $\mathrm{MgO}$ is an environmentally friendly building material that has strength and resistances due to its very strong bonds between magnesium and oxygen atoms that form $\mathrm{MgO}$ molecules [6].

3.2 Maximum dry density (MDD), optimum Moisture content (OMC) and density for PG $\mathrm{mx}$ design 
The relationship portrayed in Table 2 shows that at a low PG content of $30 \%$ the specific gravity seems to increase and reached a peak $2.13 \mathrm{gcm}^{-3}$ at $40 \% \mathrm{PG}$ content before continuously decreasing to a low 1.98 at $60 \%$ PG proportion. This maximum SG $\left(2.13 \mathrm{gcm}^{-3}\right)$ is lower than $2.60 \mathrm{gcm}^{-3}$; this means that PG has high amounts of organic matter or porous particle [ASMTM D 854-92] [7]. With this knowledge, it is safe to deduce that PG has a low holding capacity of water, and becomes saturated very quickly. The MDD of phosphogypsum was the highest at PG 50, indicating that the highest dry density obtained by compaction at its optimum moisture content is $1204 \mathrm{~g} / \mathrm{cm}^{3}$ and $22.5 \%$ OMC. Table 2.

\subsection{Unconfined compressive strength (UCS) at different moisture content and temperature}

Figure 2 shows the UCS test results against the moisture content percentages added into the mix design 1 and 2 for both raw and treated $\mathrm{PG}$ at $40{ }^{\circ} \mathrm{C}$ and $80{ }^{\circ} \mathrm{C}$.

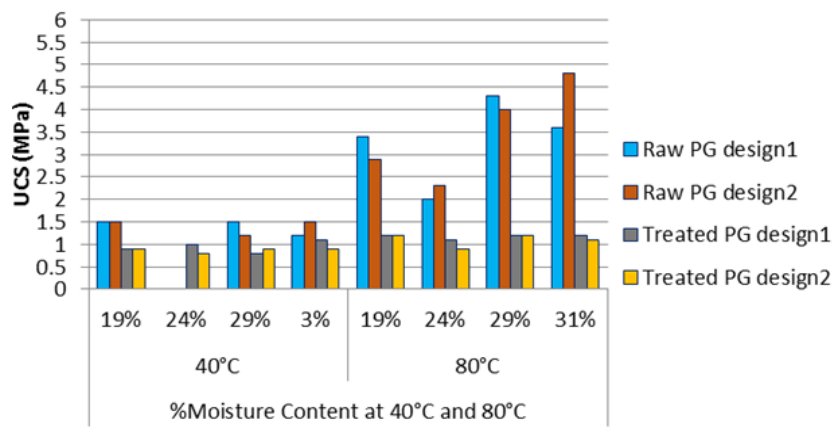

Fig. 2. UCS and moisture content bar graph at $40^{\circ} \mathrm{C}$ and $80^{\circ} \mathrm{C}$.

After curing the specimen in the oven for five days UCS was measured. The UCS values improved at the elevated temperature of $80{ }^{\circ} \mathrm{C}$ for both treated and raw $\mathrm{PG}$. However treated PG design specimen have yielded lower UCS values than Raw PG for both temperatures investigated. The UCS for treated PG vary from 0.8 to 1.2 $\mathrm{MPa}$ and from 1.2 to 4.8 MPa for Raw PG. In both cases the minimum limit range value is obtained at low temperature of $40{ }^{\circ} \mathrm{C}$ and low moisture contents while the maximum range limit is attained at the high temperature of $80{ }^{\circ} \mathrm{C}$ and high moisture content. This indicate that compressive strength of specimen is improved by curing at high temperature and high moisture contents.

\subsection{Water absorption of the produced specimen for raw and treated PG}

It is well known that clay-like products expand over time as they absorb water into their structure. According to IS 3495 [8], fly ash specimen are not expected to absorb water more than $20 \%$. To perform water absorption test specimen are oven dried at a certain temperature till they attained a constant weight. They are then cooled at room temperature and weighed (Wi). After attaining the initial weight they are totally submerged in water for $24 \mathrm{hrs}$, removed wiped out of any traces of water and weighed immediately (Wf). Using the masses measured a water absorption percentage is calculated with an equation below.

Water absorption in \% by weight $=(\mathrm{Wf}-\mathrm{Wi}) / \mathrm{Wi} \times 100$

It is preferred that specimen absorb as less water as possible ( $24 \mathrm{hr}$ absorption process) in order for them to give high durability results. After observing that the highest unconfined compressive strength was obtained at $80{ }^{\circ} \mathrm{C}$, it was then decided that specimen that will undergo inundation tests be oven dried at the same temperature $\left(80{ }^{\circ} \mathrm{C}\right)$ for five days. Upon measuring the initial weight (Wi) and the final weight (Wf), the \% water absorption was calculated using Equation 2. The overall water absorption percentage decreases with an increase in moisture content of the specimen for both the raw and treated PG material, Table 3. Even so the Raw PG specimen had the lowest water absorption percentages when compared to the treated PG. According to the South African Pavement Manual [9] the required maximum water absorption for C3 material should be $20 \%$ or less, which was achieved by raw PG material at $29 \%$ and $31 \%$ moisture content. For C4 material the limit for water absorption maximum of $30 \%$ or less which was achieved by treated PG Material from $24 \%$ to $31 \%$ moisture content.

\subsection{Durability of the produces specimen}

Since Durability is inversely proportional to \% water absorption it is theoretically correct to state that raw PG specimen will be less durable if designed with moisture contents of $24 \%$ and less while treated PG will be less durable with moisture contents of $19 \%$ or less. To achieve highest durability results these specified moisture contents must be increased to $31 \%$. 
Table 2. MDD and OMC.

\begin{tabular}{|l|l|r|r|r|}
\hline Mix design & Composition & \multicolumn{1}{|l|}{ MDD(g) } & OMC (\%) & Density $\left(\mathrm{g} / \mathrm{cm}^{3}\right)$ \\
\hline Design 4 & L20: PG30 : FA50 & 1126 & 24 & 2.04 \\
\hline Design 3 & L20: PG40 : FA40 & 1072 & 23 & 2.13 \\
\hline Design 2 & L20: PG50 : FA30 & 1204 & 22.5 & 2.05 \\
\hline Design 1 & L20: PG60 : FA20 & 1144 & 19 & 1.99 \\
\hline
\end{tabular}

Table 3. Water absorption of the produced specimen.

\begin{tabular}{|c|l|l|l|l|l|r|c|}
\hline & & \multicolumn{4}{|c|}{ Raw PG } & \multicolumn{3}{c|}{ Treated PG } \\
\hline Moisture content (\%) & PG content & Wi & Wf & $\begin{array}{l}\text { \%water } \\
\text { absorption }\end{array}$ & Wi & Wf & \%water absorption \\
\hline 15 & PG60 & 1193 & 1618 & 35.62 & 1182 & 1600 & 35.36 \\
\hline & PG50 & 1187 & 1606 & 35.30 & 1159 & 1564 & 34.94 \\
\hline 19 & PG60 & 1222 & 1608 & 31.59 & 1200 & 1595 & 32.92 \\
\hline & PG50 & 1221 & 1572 & 28.75 & 1320 & 1495 & 13.26 \\
\hline 24 & PG60 & 1260 & 1562 & 23.97 & 1274 & 1593 & 25.04 \\
\hline & PG50 & 1286 & 1606 & 24.88 & 1273 & 1545 & 21.37 \\
\hline & PG60 & 1297 & 1564 & 20.59 & 1286 & 1494 & 16.17 \\
\hline & PG50 & 1170 & 1399 & 19.57 & 1234 & 1527 & 23.74 \\
\hline & PG60 & 1358 & 1559 & 14.80 & 1271 & 1490 & 17.23 \\
\hline
\end{tabular}

manufacturing of glass, electronics, abrasives and building materials was also detected with a content of

\subsection{The mineralogy of the treated PG}

The XRD of the treated PG is shown in Figure 3.

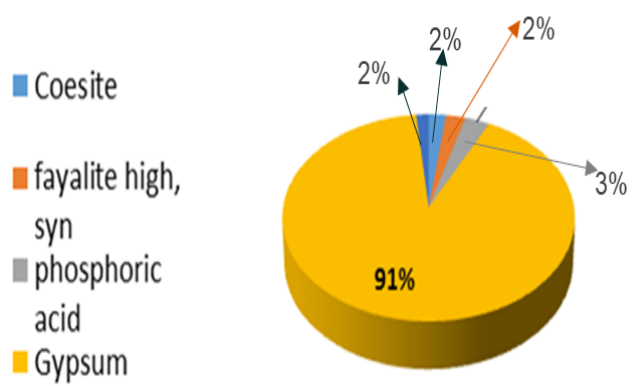

\section{Radionuclides}

Fig. 3. Mineralogy of treated PG.

The treatment of phosphogypsum with citric acid transformed the calcium sulphate initially contained in phosphogypsum from $\mathrm{CaSO}_{4}$ to $\mathrm{CaSO}_{4} \cdot 2 \mathrm{H}_{2} \mathrm{O}$ (Figure 3). The predominant constituent in the citric acid leached material corresponded to gypsum $\left(\mathrm{CaSO}_{4} \cdot 2 \mathrm{H}_{2} \mathrm{O}\right), 91 \%$, followed by phosphoric acid $\left(\mathrm{H}_{3} \mathrm{PO}_{4}\right), 3 \%$, Fayalite $\left(\mathrm{Fe}_{2} \mathrm{SiO}_{4}\right)$ with a content of $2.0 \%$ and radionuclides, $2 \%$. Fayalite is a relatively common constituent of acidic and alkaline igneous rocks. This agrees with the XRF results obtained where the predominant elements were $\mathrm{Ca}$ and $\mathrm{S}$. Coesite $\left(\mathrm{SiO}_{2}\right)$, a mineral normally used in the $1.95 \%$. The remaining constituents were those associated with the radionuclides

\section{Conclusion}

A PG leaching process through a single stage using citric acid as a solute removed $34.7 \% \mathrm{P}_{2} \mathrm{O}_{5}$ molecules, while upgrading $\mathrm{CaO}$ purity by $2.3 \%$. Furthermore radioactive materials were reduced and a large $72.3 \%$. The leaching process resulted in a more environmentally friendly yet limited strength of PG. The Minimum standard required UCS for load bearing in South Africa is 3.5 MPa. Curing PG specimen at high temperature improved the UCS results to a satisfying maximum $4.8 \mathrm{MPa}$ which made them qualifying for use as building and construction load bearing material. PG developed specimen absorbed as high as $35 \%$ water at low moisture content and as low as $13 \%$ water at high $31 \%$ moisture contents. Citric acid treated PG specimen absorbed a high water percentage when compared to raw PG. When comparing durability strength; raw PG specimen are more durable than treated PG specimen. A 50\% and $60 \%$ raw PG specimen at high $\mathrm{OMC}$ and high curing temperatures of $80{ }^{\circ} \mathrm{C}$ qualifies to be used as building, construction and backfill material.

\section{Acknowledgments}

The authors would like to thank the University of Johannesburg for providing resources to conduct the study. 


\section{References}

1. M. Schorr B. Valdez, Corros Rev. 34,1-2 (2016).

2. T. Mashifana, F.N. Okonta, F. Ntuli, Mat. Sci. 24, 3 (2018).

3. J. Mulopo D. Ikhu-Omoregbe J. Chem Eng Process Technol. 3, 129 (2012).

4. H. Tayibi, M. Choura F.A. López F.J. Alguacil. A. López-Delgado, J. Environ. Manage. 90, 8 (2009).

5. TRH4 (1996). 1-101.

6. Z. Li, Z. Ding, Y. Zhang, China, (2004).

7. ASTM D 854-92. Section IV: Specific Gravity of solids Determination.

8. IS-3495 (Part -2).

9. SANRAL, (2012) 